\title{
Impacts of CD44 knockdown in cancer cells on tumor and host metabolic systems revealed by quantitative imaging mass spectrometry
}

\author{
Mitsuyo Ohmura a , Takako Hishiki a, Takehiro Yamamoto a , Tsuyoshi Nakanishi a,b, \\ Akiko Kubo a, Kenji Tsuchihashi ${ }^{\text {c,d }}$, Mayumi Tamada ${ }^{c}$, Sakino Toue ${ }^{a}$, Yasuaki Kabe a,e, \\ Hideyuki Saya ${ }^{\mathrm{c}}$, Makoto Suematsu ${ }^{\mathrm{a}, \mathrm{e}, *}$ \\ a Department of Biochemistry, Keio University School of Medicine, Tokyo 160-8582, Japan \\ ${ }^{\mathrm{b}}$ MS Business Unit, Shimadzu Corporation, Kyoto 604-8511, Japan \\ ${ }^{c}$ Division of Gene Regulation, Institute for Advanced Medical Research, Keio University School of Medicine, Tokyo 160-8582, Japan \\ d Medicine and Biosystemic Science, Kyushu University Graduate School of Medical Sciences, Fukuoka 812-8582, Japan \\ e Japan Science and Technology Agency, Exploratory Research for Advanced Technology, Suematsu Gas Biology Project, Tokyo 160-8582, Japan
}

\section{A R T I C L E I N F O}

Article history:

Available online 11 November 2014

\section{Keywords:}

Remethylation

Transsulfuration

Reactive cysteine persulfides

Polyamines

$\mathrm{xCT}$

Cancer

\begin{abstract}
A B S T R A C T
CD44 expressed in cancer cells was shown to stabilize cystine transporter (xCT) that uptakes cystine and excretes glutamate to supply cysteine as a substrate for reduced glutathione (GSH) for survival. While targeting CD44 serves as a potentially therapeutic stratagem to attack cancer growth and chemoresistance, the impact of CD44 targeting in cancer cells on metabolic systems of tumors and host tissues in vivo remains to be fully determined. This study aimed to reveal effects of CD44 silencing on alterations in energy metabolism and sulfur-containing metabolites in vitro and in vivo using capillary electrophoresismass spectrometry and quantitative imaging mass spectrometry (Q-IMS), respectively. In an experimental model of xenograft transplantation of human colon cancer HCT116 cells in superimmunodeficient NOG mice, snap-frozen liver tissues containing metastatic tumors were examined by Q-IMS. As reported previously, short hairpin CD44 RNA interference (shCD44) in cancer cells caused significant regression of tumor growth in the host liver. Under these circumstances, the CD44 knockdown suppressed polyamines, GSH and energy charges not only in metastatic tumors but also in the host liver. In culture, HCT116 cells treated with shCD44 decreased total amounts of methionine-pool metabolites including spermidine and spermine, and reactive cysteine persulfides, suggesting roles of these metabolites for cancer growth. Collectively, these results suggest that CD44 expressed in cancer accounts for a key regulator of metabolic interplay between tumor and the host tissue.
\end{abstract}

(C) 2014 Elsevier Inc. All rights reserved.

\section{Introduction}

Methionine is an essential amino acid provided by nutrition that starts remethylation cycle to synthesize S-adenosylmethionine (SAM), a donor metabolite necessary for transfer of methyl group to DNA and proteins, playing a critical role for epigenetic modification. SAM is also decarboxylated to yield polyamines including spermidine and spermine through methionine salvage pathway which plays a crucial role for regulation of cancer proliferation [1,2]. After donating methyl group, SAM is converted to S-adenosylhomocysteine $(\mathrm{SAH})$ and then to homocysteine (Hcy) and methionine; these metabolites collectively form remethylation cycle, contributing to

\footnotetext{
* Corresponding author. Department of Biochemistry, Keio University School of Medicine, Tokyo 160-8582, Japan. Fax: +81 353633466.

E-mail address: gasbiology@z6.keio.jp (M. Suematsu).
}

epigenetic regulation. A portion of Hcy that does not recycle to generate methionine is catalyzed by cystathionine $\beta$-synthase (CBS), the rate-limiting enzyme of transsulfuration pathway that generates cystathionine. This pathway plays a crucial role in ameliorating xenobiotic toxicity for cancer chemoresistance. Cystathionine $\gamma$-lyase (CSE), the 2nd enzyme of the pathway, catalyzes cystathionine to generate cysteine (Cys), providing a substrate for glutathione synthesis. Operation of methionine cycle and glutathione synthesis requires ATP.

Besides remethylation and transsulfuration pathways, the extracellular pathway dependent on CD44/xCT complex serves as an alternative mechanism to supply Cys to cells $[3,4]$. Through this mechanism in cancer cells, extracellular cystine (Cys-Cys) has been thought to enter cells to provide Cys for glutathione synthesis, so far as CD44 knockdown breaks down xCT stabilization and suppresses the entry of cystine and reduces GSH contents in cancer cells [4]. Previous studies revealed that Cys-Cys serves as a substrate for

http://dx.doi.org/10.1016/j.niox.2014.11.005

1089-8603/@ 2014 Elsevier Inc. All rights reserved. 
Table 1

Lists of metabolites with their theoretical and actual $\mathrm{m} / \mathrm{z}$ values and $\mathrm{MS}^{2}$ ion species in positive and negative ion mode.

\begin{tabular}{|c|c|c|c|c|}
\hline \multicolumn{5}{|c|}{ Positive ion mode (Matrix: DHB) } \\
\hline \multirow[t]{3}{*}{ Compound name } & \multirow[t]{3}{*}{ Chemical formula } & \multicolumn{2}{|c|}{ Monoisotopic molecular weight } & \multirow[t]{3}{*}{ Fragments observed in $\mathrm{MS}^{2}$} \\
\hline & & Theoretical & Actual & \\
\hline & & $m / z$ & $m / z$ & \\
\hline SAM & $\mathrm{C}_{15} \mathrm{H}_{23} \mathrm{~N}_{6} \mathrm{O}_{5} \mathrm{~S}$ & 399.145 & 399.141 & $250.093,298.096,136.064$ \\
\hline $\mathrm{SAH}$ & $\mathrm{C}_{14} \mathrm{H}_{20} \mathrm{~N}_{6} \mathrm{O}_{5} \mathrm{~S}$ & 385.129 & 385.126 & $250.087,136.063,134.027$ \\
\hline Spermidine & $\mathrm{C}_{7} \mathrm{H}_{19} \mathrm{~N}_{3}$ & 146.166 & 146.155 & $129.027,72.058,112.088$ \\
\hline Spermine & $\mathrm{C}_{10} \mathrm{H}_{26} \mathrm{~N}_{4}$ & 203.224 & 203.212 & $129.139,112.104,84.082$ \\
\hline Adenosine & $\mathrm{C}_{10} \mathrm{H}_{13} \mathrm{~N}_{5} \mathrm{O}_{4}$ & 268.105 & 268.086 & 136.059 \\
\hline \multicolumn{5}{|c|}{ Negative ion mode (Matrix: 9AA) } \\
\hline \multirow[t]{3}{*}{ Compound name } & Chemical formula & \multicolumn{2}{|c|}{ Monoisotopic molecular weight } & \multirow[t]{3}{*}{ Fragments observed in $\mathrm{MS}^{2}$} \\
\hline & & Theoretical & Actual & \\
\hline & & $m / z$ & $m / z$ & \\
\hline UDP-HexNAc & $\mathrm{C}_{17} \mathrm{H}_{27} \mathrm{~N}_{3} \mathrm{O}_{17} \mathrm{P}_{2}$ & 606.074 & 606.068 & $\begin{array}{l}385.031,403.030,282.039,272.954,323.046,305.018 \text {, } \\
362.055\end{array}$ \\
\hline GSH & $\mathrm{C}_{10} \mathrm{H}_{17} \mathrm{~N}_{3} \mathrm{O}_{6} \mathrm{~S}$ & 306.076 & 306.067 & $\begin{array}{l}\text { 254.087, 179,050, 272.072, 143,048, 159,932, } 210.092 \\
128.030,171.032\end{array}$ \\
\hline GSSG & $\mathrm{C}_{20} \mathrm{H}_{32} \mathrm{~N}_{6} \mathrm{O}_{12} \mathrm{~S}_{2}$ & 611.144 & 611.137 & $\begin{array}{l}306.071,272.086,338.058,254.079,482.103,304.058, \\
288.058,593.121\end{array}$ \\
\hline $\mathrm{GSO}_{3}^{-}$ & $\mathrm{C}_{10} \mathrm{H}_{17} \mathrm{~N}_{3} \mathrm{O}_{9} \mathrm{~S}$ & 354.061 & 354.038 & $\begin{array}{l}\text { 179.036, 336.099, 225.006, 210.075, 135.050, 254.062, } \\
\text { 193.063, 143.031, 261.002 }\end{array}$ \\
\hline $\mathrm{GSSO}_{3}^{-}$ & $\mathrm{C}_{10} \mathrm{H}_{17} \mathrm{~N}_{3} \mathrm{O}_{9} \mathrm{~S}_{2}$ & 386.033 & 386.008 & $\begin{array}{l}306.058,179.036,254.062,272.071,288.049,368.000 \\
160.000,143.040,210.076,194.050\end{array}$ \\
\hline ATP & $\mathrm{C}_{10} \mathrm{H}_{16} \mathrm{~N}_{5} \mathrm{O}_{13} \mathrm{P}_{3}$ & 505.988 & 505.986 & $408.046,272.955,158.924,176.934$ \\
\hline ADP & $\mathrm{C}_{10} \mathrm{H}_{15} \mathrm{~N}_{5} \mathrm{O}_{10} \mathrm{P}_{2}$ & 426.022 & 426.032 & $328.070,134.048$ \\
\hline AMP & $\mathrm{C}_{10} \mathrm{H}_{14} \mathrm{~N}_{5} \mathrm{O}_{7} \mathrm{P}$ & 346.055 & 346.094 & $210.998,149.988,192.991,134.041$ \\
\hline Gln & $\mathrm{C}_{5} \mathrm{H}_{10} \mathrm{~N}_{2} \mathrm{O}_{3}$ & 145.061 & 145.060 & $127.053,109.042$ \\
\hline Glu & $\mathrm{C}_{5} \mathrm{H}_{9} \mathrm{NO}_{4}$ & 146.045 & 146.047 & $128.022,102.046$ \\
\hline Taurine & $\mathrm{C}_{2} \mathrm{H}_{7} \mathrm{NO}_{3} \mathrm{~S}$ & 124.007 & 124.010 & $79.958,106.978$ \\
\hline Asp & $\mathrm{C}_{4} \mathrm{H}_{7} \mathrm{NO}_{4}$ & 132.030 & 132.031 & $88.038,115.013$ \\
\hline Malate & $\mathrm{C}_{4} \mathrm{H}_{6} \mathrm{O}_{5}$ & 133.014 & 133.015 & $115.006,71.018$ \\
\hline
\end{tabular}

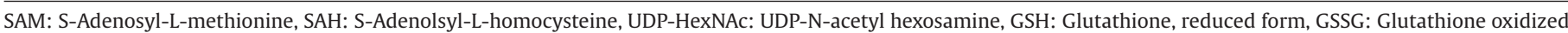
form, $\mathrm{GSO}_{3}{ }^{-}$: Glutathione sulfonate, $\mathrm{GSSO}_{3}{ }^{-}$: Glutathione S-sulfonate.

CBS and CSE to generate cysteine hydropersulfide (Cys-SSH) as a primary product of these enzymes. This reactive persulfide can react with reduced glutathione (GSH) to form glutathione hydropersulfide (GSSH) and other derivatives including cysteine-glutathione disulfide (Cys-SSG) and hydrogen sulfide anion (HS') and other polysulfide derivatives of thiol-containing peptides and proteins [5]. Compared with glutathione and hydrogen sulfide, Cys-SSH derivatives were superior nucleophiles and reductants and capable of detoxifying nucleophiles [5], benefiting amelioration of oxidative stress in cancer cells.

Since methionine and cysteine might be derived from host tissues during cancer development, it is not unreasonable to hypothesize that CD44 targeting by RNA interference or small molecular reagents does not only contribute to cancer regression but also alter metabolic systems of the host tissues. We have recently developed quantitative imaging mass spectrometry (Q-IMS) as a novel method to collect quantitative information of many metabolites in tumor-bearing tissues. Using this technique combined with super-immunodeficient mice for xenograft transplantation of human-derived cancer cells, the current study aimed to examine influence of CD44 knockdown in human-derived colon cancer HCT116 cells on metabolic systems in metastatic tumors and the liver as a host tissue. The results showed that the CD44 knockdown suppressed polyamines, GSH and energy charges not only in metastatic tumors but also in the host liver, suggesting that CD44 in cancer cells support the metabolic interplay between tumors and the host tissue, benefiting cancer proliferation and survival.

\section{Materials and methods}

\subsection{Stable CD44 interference with shRNA}

Using expression vectors encoding a shRNA specific for human CD44 mRNA or a scrambled shRNA obtained from Origene Technologies (Rockville, MD), we introduced it into HCT 116 cells by transfection with Lipofectamine 2000 [4]. The sequence of shRNA used for CD44 knockdown (shCD44) throughout all studies was 5'GCTGACCTCTGCAAGGCTTTCAATAGCAC-3'. The control non-targeting shRNA sequence was 5'-GCACTACCAGAGCTAACTCAGATAGTACT-3', designated as control shRNA unless otherwise mentioned.

\subsection{Human-derived cancer xenografts in livers of superimmunodeficient mice}

All animal experiments were carried out in accordance with the guidelines of Experimental Animal Committee of Keio University School of Medicine. Human colon cancer (HCT116) cells were transfected stably with non-target control shRNA or with shCD44. The cells were injected into the spleen of superimmunodeficient NOG (NOD/SCID/IL-2R $\gamma^{\text {null }}$ ) mice as described previously [6-8]. In brief, HCT116 cells were injected into the spleen of male NOG mice aged at $11 \sim 14$ weeks at $1 \times 10^{6}$ cells/mouse. Two weeks after transplantation, liver lobules of the mice fasted for 17 hours were excised under sevoflurane anesthesia and snap-frozen with liquid nitrogen. To examine tumor growth in vivo, $5-\mu \mathrm{m}$ thickness cryosections were stained with hematoxylin and eosin (H\&E), serving as 
Table 2

Composition of culture medium used in the study $(\mathrm{g} / \mathrm{L})$.

\begin{tabular}{|c|c|c|c|}
\hline & DMEM-(A) & DMEM-(B) & DMEM-(C) \\
\hline \multicolumn{4}{|l|}{ Amino acids } \\
\hline L-Alanine & 0.00445 & 0.00445 & 0.0356 \\
\hline L-Arginine $\cdot \mathrm{HCl}$ & 0.1475 & 0.1475 & 0.084 \\
\hline $\mathrm{L}$-Asparagine $\cdot \mathrm{H}_{2} \mathrm{O}$ & 0.0075 & 0.0075 & 0.06 \\
\hline L-Aspartic acid & 0.00665 & 0.00665 & 0.0532 \\
\hline L-Cystine $\cdot 2 \mathrm{HCl}$ & 0.03129 & 0.01756 & \\
\hline L-Cysteine $\cdot \mathrm{HCl} \cdot \mathrm{H}_{2} \mathrm{O}$ & 0.01756 & 0.03129 & \\
\hline L-Glutamic acid & 0.00735 & 0.00735 & 0.0588 \\
\hline L-Glutamine & 0.365 & $0.365^{*}$ & 0.584 \\
\hline Glycine & 0.01875 & 0.01875 & 0.03 \\
\hline L-Histidine $\cdot \mathrm{HCl} \cdot \mathrm{H}_{2} \mathrm{O}$ & 0.03148 & 0.03148 & 0.042 \\
\hline L-Isoleucine & 0.05447 & 0.05447 & 0.105 \\
\hline L-Leucine & 0.05905 & $0.05905^{*}$ & 0.105 \\
\hline L-Lysine $\cdot \mathrm{HCl}$ & 0.09125 & $0.09125^{*}$ & 0.146 \\
\hline L-Methionine & 0.01724 & 0 or $0.01724^{* *}$ & 0.03 \\
\hline L-Phenylalanine & 0.03548 & 0.03548 & 0.066 \\
\hline L-Proline & 0.01725 & 0.01725 & 0.046 \\
\hline L-Serine & 0.02625 & 0.02625 & 0.042 \\
\hline L-Threonine & 0.05345 & 0.05345 & 0.095 \\
\hline L-Tryptophan & 0.00902 & 0.00902 & 0.016 \\
\hline $\mathrm{L}$-Tyrosine $\cdot 2 \mathrm{Na} \cdot 2 \mathrm{H}_{2} \mathrm{O}$ & 0.05579 & 0.05579 & 0.104 \\
\hline L-Valine & 0.05285 & 0.05285 & 0.094 \\
\hline \multicolumn{4}{|l|}{ Inorganic salts } \\
\hline $\mathrm{CaCl}_{2} \cdot 2 \mathrm{H}_{2} \mathrm{O}$ & 0.1545 & $0.1545^{*}$ & \\
\hline $\mathrm{CaCl}_{2} \cdot 9 \mathrm{H}_{2} \mathrm{O}$ & & & 0.265 \\
\hline $\mathrm{CuSO}_{4} \cdot 5 \mathrm{H}_{2} \mathrm{O}$ & 0.0000013 & 0.0000013 & \\
\hline $\mathrm{Fe}\left(\mathrm{NO}_{3}\right)_{3} \cdot 9 \mathrm{H}_{2} \mathrm{O}$ & 0.00005 & 0.00005 & 0.0001 \\
\hline $\mathrm{FeSO}_{4} \cdot 7 \mathrm{H}_{2} \mathrm{O}$ & 0.000417 & 0.000417 & \\
\hline $\mathrm{MgCl}_{2} \cdot 6 \mathrm{H}_{2} \mathrm{O}$ & 0.0612 & $0.0612^{*}$ & \\
\hline $\mathrm{MgSO}_{4}$ & 0.04884 & $0.04884^{*}$ & 0.09767 \\
\hline $\mathrm{KCl}$ & 0.3118 & 0.3118 & 0.4 \\
\hline $\mathrm{NaCl}$ & 6.996 & 6.996 & 4.75 \\
\hline $\mathrm{NaHCO}_{3}$ & 1.2 & $1.2^{*}$ & 3.7 \\
\hline $\mathrm{Na}_{2} \mathrm{HPO}_{4}$ & 0.07102 & 0.07102 & \\
\hline $\mathrm{NaH}_{2} \mathrm{PO}_{4}$ & 0.0543 & 0.0543 & 0.109 \\
\hline $\mathrm{ZnSO}_{4} \cdot 7 \mathrm{H}_{2} \mathrm{O}$ & 0.000432 & 0.000432 & \\
\hline \multicolumn{4}{|l|}{ Vitamins } \\
\hline D-Biotin & 0.0000035 & 0.0000035 & \\
\hline Choline chloride & 0.00898 & 0.00898 & 0.004 \\
\hline Folic acid & 0.00266 & 0.00266 & 0.004 \\
\hline myo-Inositol & 0.0126 & 0.0126 & \\
\hline i-Inositol & & & 0.0072 \\
\hline Niacinamide & 0.00202 & 0.00202 & 0.004 \\
\hline D-Pantothenic acid·1/2Ca & 0.00224 & 0.00224 & 0.004 \\
\hline Pyridoxal·HCl & 0.002 & 0.002 & \\
\hline Pyridoxine $\cdot \mathrm{HCl}$ & 0.002031 & 0.000031 & 0.004 \\
\hline Riboflavin & 0.000219 & 0.00219 & 0.0004 \\
\hline Thiamine $\cdot \mathrm{HCl}$ & 0.00217 & 0.00217 & 0.004 \\
\hline Vitamin $\mathrm{B}_{12}$ & 0.00068 & 0.00068 & \\
\hline \multicolumn{4}{|l|}{ Others } \\
\hline D-Glucose & 3.15 & 3.15 & 3.15 \\
\hline HEPES & & 3.5745 & 5.958 \\
\hline Hypoxanthine & 0.00244 & 0.0021 & \\
\hline Linoleic acid & 0.000042 & 0.000042 & \\
\hline Putrescine $\cdot 2 \mathrm{HCl}$ & 0.000081 & 0.000081 & \\
\hline Pyruvic acid·Na & 0.055 & 0.055 & \\
\hline DL-Thioctic acid & 0.000105 & 0.000105 & \\
\hline Thymidine & 0.000365 & 0.000365 & \\
\hline Phenol red & 0.00863 & & 0.01493 \\
\hline
\end{tabular}

DMEM-(A): DMEM F-12 (Sigma-Aldrich, D8062), DMEM-(B): DMEM F-12(SigmaAldrich, D9785), DMEM-(C): modified DMEM.

* As DMEM F-12 does not contain these components, these are added when the medium is prepared.

** Experiments determining effects of the presence and absence of methionine were performed using DMEM-(B).

resources of microscopic images for calculating cross-sectional percentages of tumor regions with Image J software [9].

\subsection{Quantitative imaging mass spectrometry (Q-IMS)}

Snap-frozen tissues collected from the non-targeting control- or shCD44-transfected HCT116 cell-derived tumor-bearing livers were used for, Q-IMS according to our previous methods [7,10,11,12]. Briefly, as a matrix, $5 \mathrm{mg} / \mathrm{mL}$ 9-aminoacridine (Merck Schucardt, Hohenbrunn, Germany) in 80\% ethanol solution was sprayed over the 5- $\mu \mathrm{m}$ thickness liver sections which were thaw-mounted on ITOcoated glass slides (Bruker Daltonik GmbH, Bremen, Germany). MALDI IT-TOF mass spectrometer (Shimadzu Corp., Kyoto, Japan) allowed us to collect the data in the negative ion mode with the recording mass range from $\mathrm{m} / \mathrm{z} 304$ to 670 . After selecting the region of interests (ROIs) by light microscopic observations, a series of repeated laser irradiation at 100 times per spot was performed at 10 $\mu \mathrm{m}$ pitch intervals at $250 \times 250$ spots, giving 62,500 data points in total for each scan. Averaged spectra from each ROIs were generated and statistically analyzed by house-made software SIMtools (Shimadzu Imaging Mass spectrometry toolbox for MATLAB ${ }^{(R)}$ ) as described previously. To evaluate small molecules such as amino acids, we performed the measurement with the mass range of $m / z$ $86-400$ at $25-\mu \mathrm{m}$ intervals at $100 \times 100$ spots. Mass peaks of metabolites collected from tissue sections were identified by comparing MS/MS fragment patterns with those collected from standard reagents (Table 1 ).

CE-MS analyses allowed us to determine contents of varied metabolites in a portion of tumor-bearing liver tissues which was adjacent to the corresponding IMS section as described previously $[7,10,12]$. To calculate the apparent contents in parenchymal and tumor regions of tumor-bearing livers $\left(\left[C_{\mathrm{p}}\right]_{\mathrm{app}}\right.$ and $\left[C_{\mathrm{T}}\right]_{\mathrm{app}}$, respectively), the following equations were used after calculating crosssectional percentage areas of tumor regions $\left(O_{\mathrm{T}} \%\right)$ that are calculated in digital tissue images collected from H\&E stained sections as described elsewhere:

$I_{\text {Average }}=\left(I_{\mathrm{P}} \times O_{\mathrm{P}}\right) / 100+\left(I_{\mathrm{T}} \times O_{\mathrm{T}}\right) / 100, O_{\mathrm{P}}+O_{\mathrm{T}}=100(\%)$

$\left[C_{\mathrm{T}}\right]_{\mathrm{app}}=\left[C_{\mathrm{CE}-\mathrm{MS}}\right] \times\left(I_{\mathrm{T}} / I_{\text {Average }}\right)$

$\left[C_{\mathrm{p}}\right]_{\mathrm{app}}=\left[C_{\mathrm{CE}-\mathrm{MS}}\right] \times\left(I_{\mathrm{p}} / I_{\text {Average }}\right)$

$C_{i}=\left[C_{\text {CE-MS }}\right] \times\left(I_{(i)} / I_{\text {Average }}\right)$

$I_{\mathrm{T}}, I_{\mathrm{p}}$ and $I_{\text {Average }}$ are MALDI signal intensities measured in regions of tumor metastases, liver parenchyma and the whole tissue section, respectively. $O_{\mathrm{T}}$ and $O_{\mathrm{p}}$ are the percentage areas of tumor regions and liver parenchymal regions, respectively. In order to calculate the values of $\left[C_{\mathrm{T}}\right]_{\mathrm{app}}$ and $\left[C_{\mathrm{p}}\right]_{\mathrm{app}}$, we used the equation (2) from $2 \sim 4$ sets of IMS data paired with CE-MS data for individual mice in each group. To construct an ion-content map, MALDI-MS data were converted to Analyze format, a common multidimensional biomedical imaging format file which contains MALDI signal intensity at each pixel I $(i)$, and equation (4) was used to calculate the apparent contents of metabolites of interest at each pixel " $i$ " (Ci).

We attempted to visualize methionine-derived metabolites such as S-adenosylmethionine (SAM), S-adenosylhomocysteine (SAH), spermidine and spermine using $30 \mathrm{mg} / \mathrm{mL}$ 2,5-dihydroxybenzoic acid (DHB) in 70\% methanol solution as a matrix for positive-mode MALDI [11]. To avoid influence of the noise induced by DHB, we measured with the scanning mass range of $\mathrm{m} / \mathrm{z} 140 \sim 300$ and $\mathrm{m} / \mathrm{z} 350 \sim 500$ at $25-\mu \mathrm{m}$ intervals at $100 \times 100$ spots.

In separate sets of experiments, glutathione sulfonate $\left(\mathrm{GSO}_{3}^{-}\right)$and glutathione $\mathrm{S}$-sulfonate $\left(\mathrm{GSSO}_{3}{ }^{-}\right)$were measured. As described previously, $\mathrm{GSO}_{3}{ }^{-}$is a terminal oxidized product yielded from glutathione. On the other hand, $\mathrm{GSSO}_{3}{ }^{-}$is a terminal oxidized product yielded in the presence of $\mathrm{H}_{2} \mathrm{~S} / \mathrm{HS}^{-}$under atmospheric MALDI conditions [10], serving as an index of endogenous persulfide generation. In these experiments, we did not calculate $\left[\mathrm{C}_{\mathrm{CE}-\mathrm{MS}}\right]$ and $\mathrm{C} i$, because their generation rates are different between CE-MS and MALDI imaging. Instead, the data of $\mathrm{GSO}_{3}{ }^{-}$and $\mathrm{GSSO}_{3}{ }^{-}$were evaluated by 

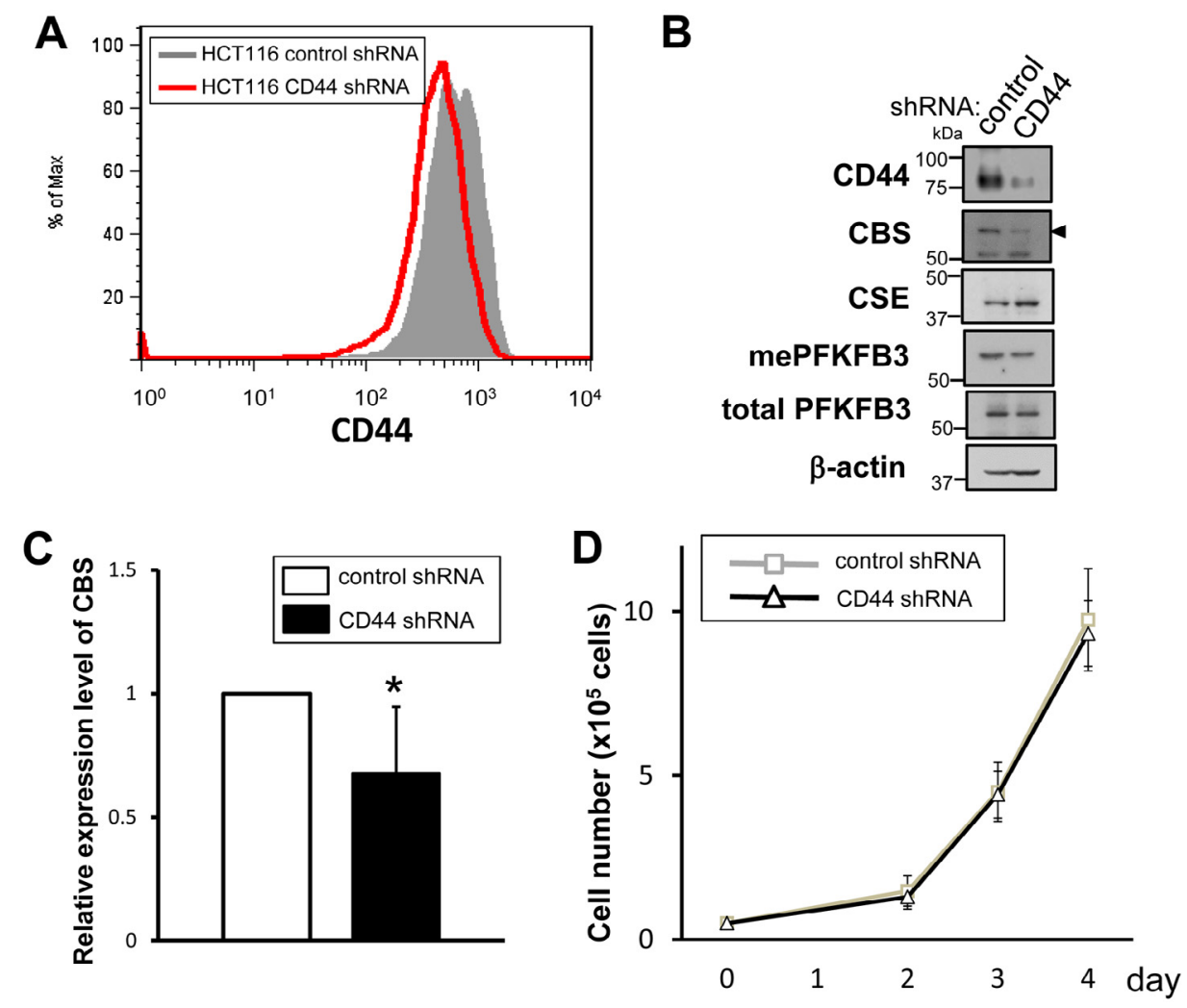

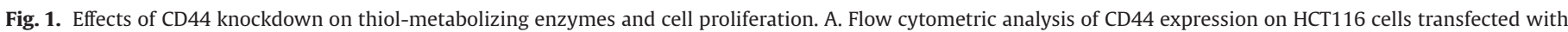

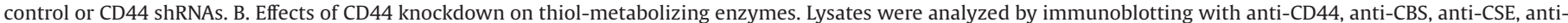

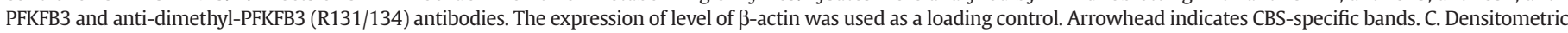

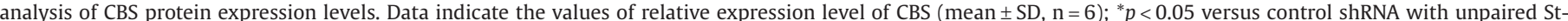

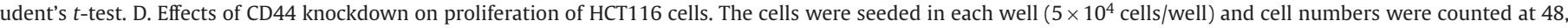

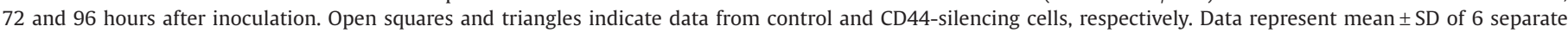
experiments. ${ }^{*} p<0.05$ versus the HCT116 cells with control shRNA (ANOVA with Fisher's multiple comparison test).

measuring their mass peaks. These experiments were carried out using a negative mode in the presence of 9 -aminoacridine as a matrix reagent.

Compositions of culture medium used for the current study were described in Table 2. DMEM-(A) was a standard culture medium (DMEM F-12, Sigma-Aldrich) used for culturing HCT116 cells in the atmospheric conditions (95\% Air / 5\% $\mathrm{CO}_{2}$ ) at $37^{\circ} \mathrm{C}$. DMEM-(B) was the methionine-free DMEM F-12 available from Sigma-Aldrich. DMEM- $(C)$ was used to examine effects of the absence of cystine and cysteine in the culture. DMEM-(C) was a generous gift from Ajinomoto Co., Inc. (Kawasaki City, Japan). In these experiments, $0.02403 \mathrm{~g} / \mathrm{L}$ of L-cystine, that is comparable to cystine contents in DMEM-(A), was added to DMEM-(C), and used for the control experiments. Unless otherwise mentioned, DMEM-(A) was used as a standard culture medium for experiments in vitro.

\subsection{Measurements of monobromobimane adducts to assess reactive cysteine persulfides}

For culture experiments, $2 \times 10^{4} \mathrm{HCT} 116$ cells treated with nontarget shRNA or those with shCD44 were cultured in $5 \% \mathrm{CO}_{2}$ at $37{ }^{\circ} \mathrm{C}$ in DMEM F-12 medium (Sigma-Aldrich, St Louis, MO) supplemented with $10 \%$ fetal bovine serum and $1 \%$ penicillin-streptomycin (Invitrogen, Carlsbad, CA) for 48 hrs, and used for viability study in the presence or absence of different concentrations of methionine and/or propargylglycine (PPG, Sigma-Aldrich, US), a potent inhibitor of cystathionine $\gamma$-lyase (CSE) $[13,14]$. The cell viability was examined by Cell Counting Kit-8 (CCK-8 kit) (Dojindo Laborato- ries, Kumamoto, Japan). When necessary, the cells were frozen and thawed to measure metabolites using capillary electrophoresismass spectrometry (CE-MS) as described previously [15]. In separate sets of experiments under the identical protocols, we determined reactive cysteine persulfides using LC-MS/MS supported by monobromobimane derivatization method [16]. Briefly, cells in culture were washed with PBS twice and plunged into methanol containing $50 \mathrm{nM}$ D-camphor-10-sulfonic acid (CSA) as an internal standard. Cell extracts and cultured medium were collected and the samples were thoroughly mixed with $0.5 \mathrm{~mL}$ deionized water and $1 \mathrm{~mL}$ chloroform, and centrifuged at $12,000 \mathrm{~g}$ for $15 \mathrm{~min}$ at $4{ }^{\circ} \mathrm{C}$. The upper aqueous phase was filtered through a 5-kDa cutoff filter (Ultrafree-MC UFC3LCC; Millipore, Billerica, MA) to remove protein precipitates. After the lyophilization of filtrates, the precipitates were dissolved in $50 \mu \mathrm{L}$ deionized water. Subsequently, the samples were incubated with $2 \mathrm{mM}$ monobromobimane (MBB) on ice for $5 \mathrm{~min}$. Because of its insolubility, MBB was predissolved in a minimum volume of DMSO. MBB derivatives in the cell extracts were determined using a Nexera UHPLC system coupled with an LCMS-8030 triple quadrupole mass spectrometer (Shimadzu, Kyoto, Japan) as an LC-MS/MS instrument. Separation was achieved on a C18 reversed-phase column (ACQUITY CSH C18, $1.7 \mu \mathrm{m}, 2.1 \times 150 \mathrm{~mm}$; Waters, Milford, MA) with a pre-column (ACQUITY UPLC CSH C18 VanGuard, $1.7 \mu \mathrm{m}, 2.1 \times 5 \mathrm{~mm}$; Waters). The MBB derivatives were eluted with acetonitrile gradients containing $0.1 \%$ formic acid: $5 \%$ $\mathrm{CH}_{3} \mathrm{CN}$ for $2.5 \mathrm{~min}$, gradient to $13 \% \mathrm{CH}_{3} \mathrm{CN}$ for $2.5 \mathrm{~min}$, gradient to $20 \% \mathrm{CH}_{3} \mathrm{CN}$ for $4 \mathrm{~min}$, gradient to $50 \% \mathrm{CH}_{3} \mathrm{CN}$ for $30 \mathrm{sec}$, gradient to $98 \% \mathrm{CH}_{3} \mathrm{CN}$ for $3 \mathrm{~min}$, and held for $2.5 \mathrm{~min}$. The injection volume 

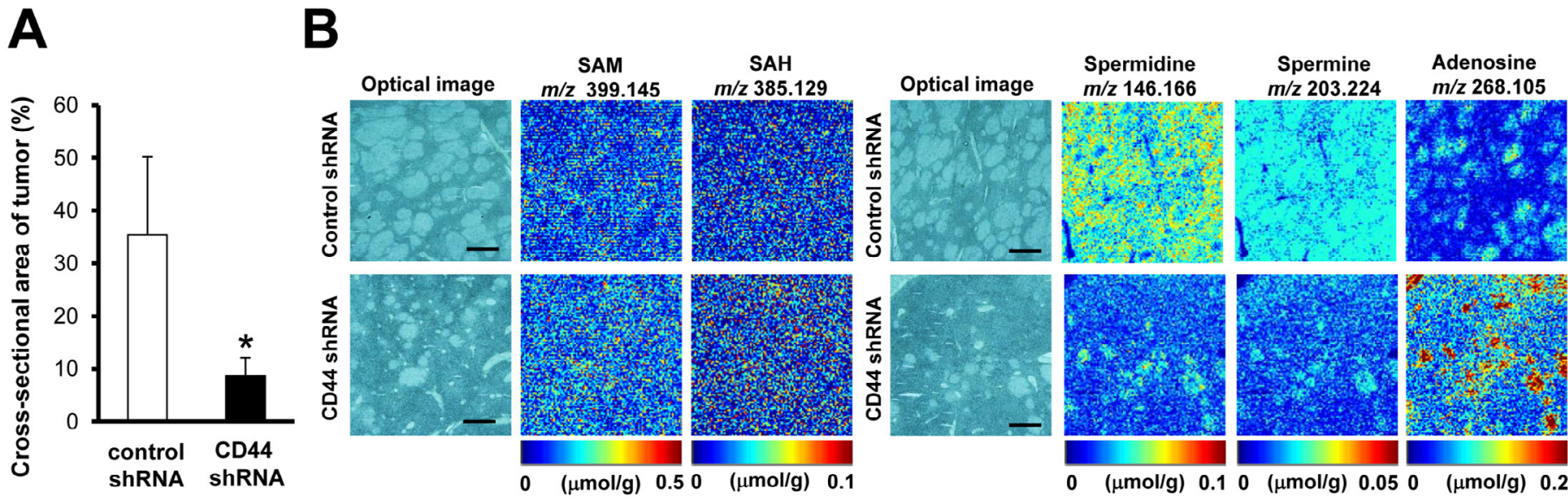

C
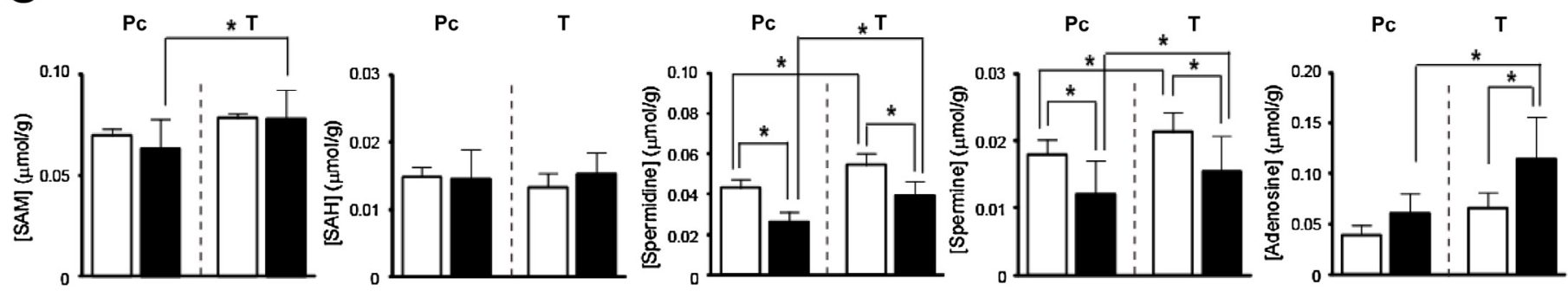

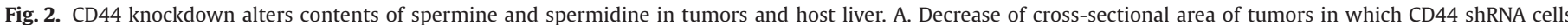

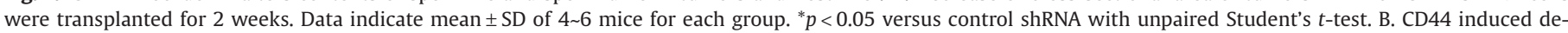

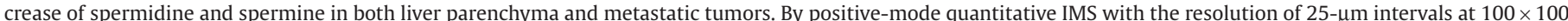

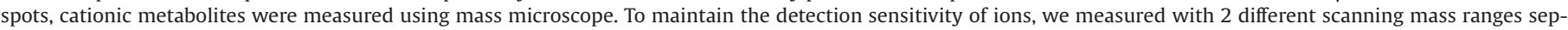

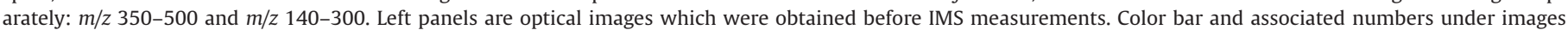

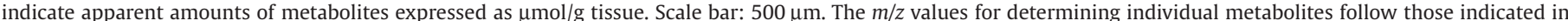

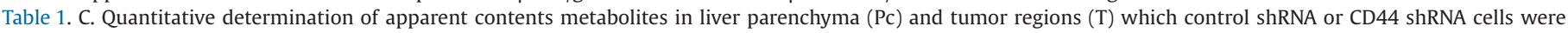

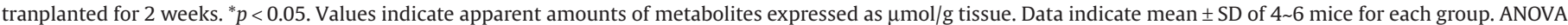
with Fisher's multiple comparison test was used.

was $10 \mu \mathrm{L}$. Column oven was kept at $40{ }^{\circ} \mathrm{C}$ and the flow rate was set to $0.25 \mathrm{~mL} / \mathrm{min}$. Optimization of multiple reaction monitoring (MRM) transition for the MBB derivatives was automatically performed by the built-in algorithm of the LCMS-8030; and the optimized MRM transitions were $m / z 413.10>191.15$ for sulfidedibimane (SDB) on negative mode, $\mathrm{m} / z 326.10>193.15$ for homocysteine-bimane (Hcy-bimane), $m / z 358.10>192.00$ for homocysteine persulfide-bimane (Hcy-S-bimane), $m / z$ 344.15 $>223.00$ for cysteine persulfide-bimane (Cys-S-bimane), and $\mathrm{m} / \mathrm{z}$ $530.20>191.95$ for glutathione persulfide-bimane (GS-S-bimane) in positive mode. The transition of CSA was monitored for $m / z$ $231.10>80.10$ in negative mode. Retention time was considered using the standard of the derivatives according to the LC condition described above. The interface ionization potential was set at $4.5 \mathrm{kV}$ with a temperature of $400{ }^{\circ} \mathrm{C}$. The flow rates of nebulizer and drying gases were set at 1.5 and $10 \mathrm{~L} / \mathrm{min}$, respectively. The standard reagents of MBB derivatives were purchased from Shinsei Chemical (Osaka, Japan).

\subsection{Western blotting}

Cell extracts were mixed with equivalent volume of $2 \times$ Laemmli sample buffer (62.55 mM Tris-HCl; pH6.8, 2\% SDS, 25\% Glycerol, and $0.01 \%$ Bromophenolblue) with or without (for the detection of CD44) $10 \%(w / v) 2$-mercaptoethanol. The equivalent amounts of proteins $(25 \mu \mathrm{g} /$ lane $)$ were separated by $10 \%$ SDS-PAGE and transferred onto PVDF membranes. The membranes were blocked in PBST $(0.15 \mathrm{M} \mathrm{NaCl}, 10 \mathrm{mM}$ Tris-HCl; pH7.5, and 0.1\% Tween20) containing $3 \%(\mathrm{w} / \mathrm{v})$ skim milk for $1 \mathrm{~h}$ at room temperature. Subsequently, the membranes were probed with the primary antibody for overnight at $4{ }^{\circ} \mathrm{C}$. Following the incubation of primary antibodies, the membranes were incubated with the appropriate HRP-conjugated secondary antibody for $2 \mathrm{~h}$ at room temperature. Signals were visualized by ECL Prime (GE Healthcare, Amersham, UK).

The following primary antibodies were used in Western blotting: anti-CD44 mouse monoclonal (ab6124, Abcam, Cambridge, UK; 3,000× dilution), anti-CSE mouse monoclonal (H00001491-M03, Abnova, Taipei, Taiwan; 7,000 $\times$ dilution), anti-CBS mouse monoclonal (H00000875-M01, Abnova; 7,000× dilution), anti-beta actin mouse monoclonal (A1978, Sigma-Aldrich, St. Louis, MO; 10,000× dilution), anti-PFKFB3 mouse monoclonal (H00005209-M08, Abnova; $2,000 \times$ dilution), and anti-asymmetrically dimethylated PFKFB3 polyclonal antibody were generated by Sigma-Aldrich Japan (Ishikari, Japan; 5,000× dilution) [10].

\subsection{Statistical analysis}

All quantitative results are presented as the mean \pm SD of independent experiments. Statistical differences between two groups were analyzed by unpaired Student's $t$-test. For experiments with multiple comparisons, data were first analyzed by analysis of 


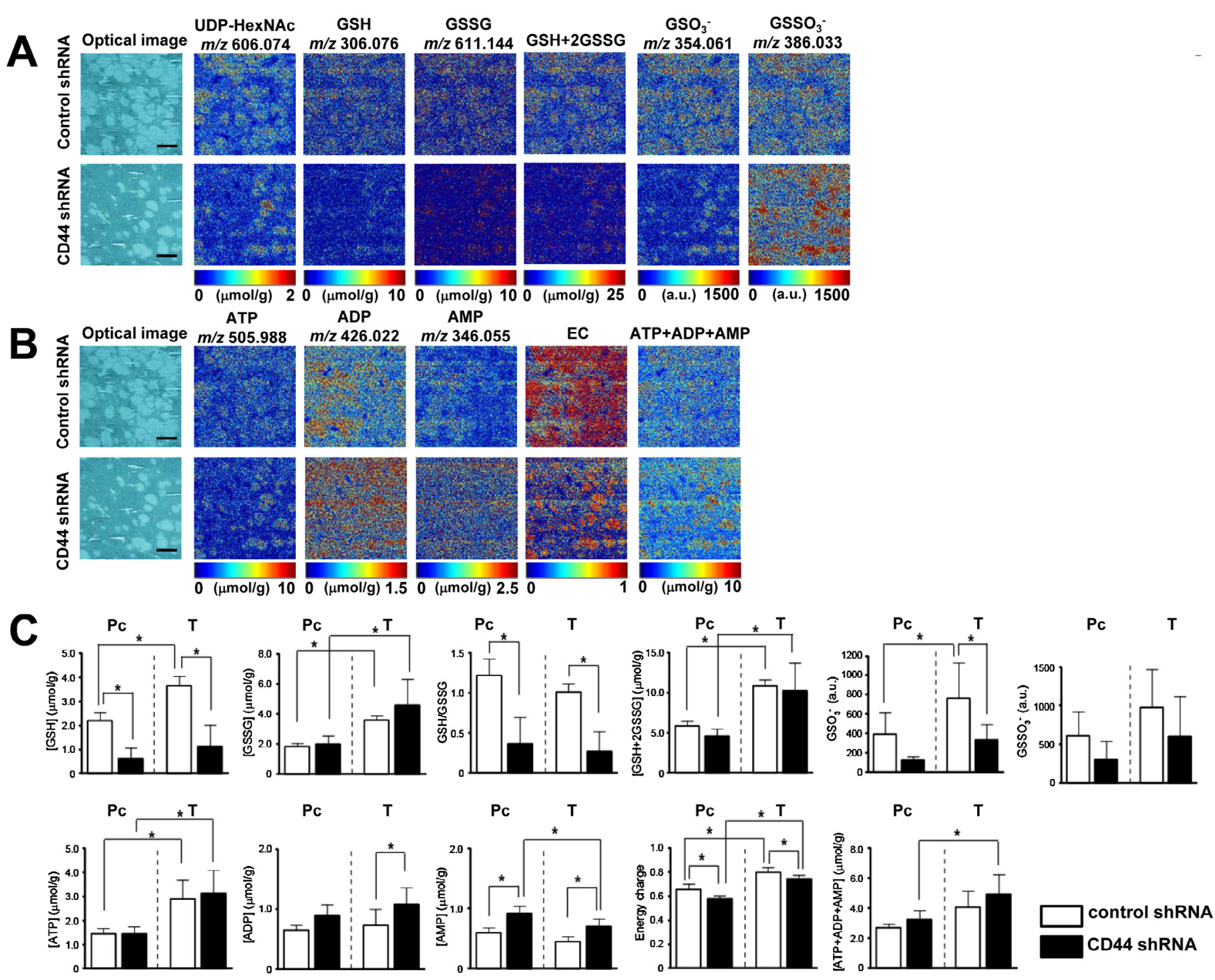

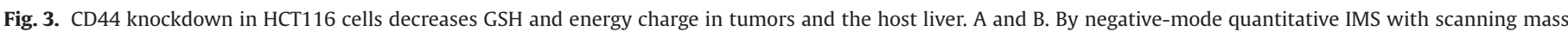

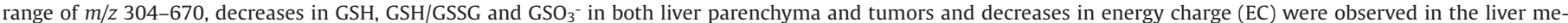

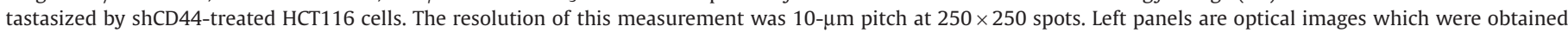

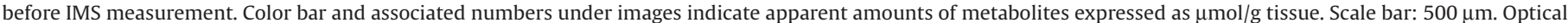

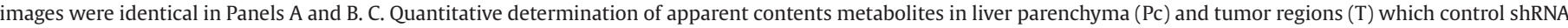

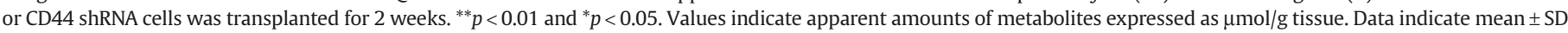
of 4 6 mice for each group. ANOVA with Fisher's multiple comparison test was used.

variance (ANOVA) with Fisher's least significant difference. $P<0.05$ was considered statistically significant.

\section{Results}

\subsection{Characterization of HCT116 cells treated with CD44 knockdown}

Fig. 1 indicated characterization of HCT116 cells knocking down CD44 by shRNA treatment. As judged by FACS analysis, short hairpin RNA interference for CD44 (shCD44) down-regulated expression of CD44 in HCT116 cells (Fig. 1A). Western blot analyses showed downregulation of CD44 proteins that coincided with significant suppression of CBS protein but not that of CSE and methylated PFKFB3 and total PFKFB3, which are determinants of glucose oxidation and energy metabolism (Figs. 1B and 1C) [10]. Under these circumstances, the cancer cells treated with shCD44 exhibited com- parable levels of cell proliferation to those treated with control shRNA during 4 days after inoculation of the cells.

\subsection{Positive-mode Q-IMS of the liver bearing HCT116-derived tumors}

HCT116 cells treated with control shRNA or those with shCD44 were injected into spleens of NOG mice, and liver tissues were examined by Q-IMS (Fig. 2). As seen in Fig. 2A, shCD44 treatment significantly diminished cross-sectional areas of metastatic tumors in the liver tissues. Figs. $2 \mathrm{~B}$ and $2 \mathrm{C}$ depicted representative pictures of metabolites and their quantitative contents in parenchyma (Pc) and tumors (T); all metabolites were measured by positive ion mode using DHB as a matrix reagent. As seen, SAM $(m / z$ 399.145) and $\mathrm{SAH}(\mathrm{m} / \mathrm{z} 385.129)$ were detectable in a manner comparable between Pc and T. Contents of these metabolites were not greatly 
A

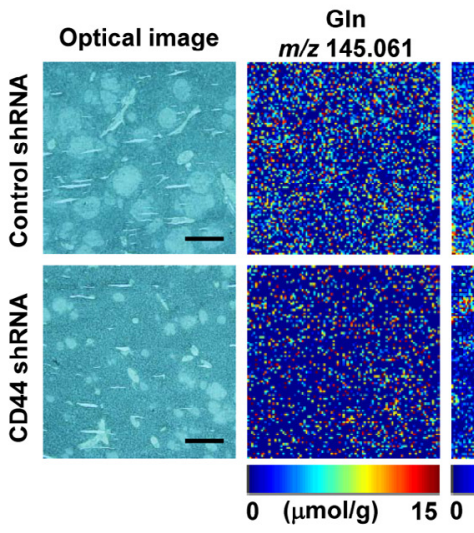

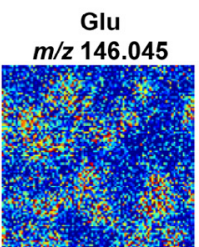
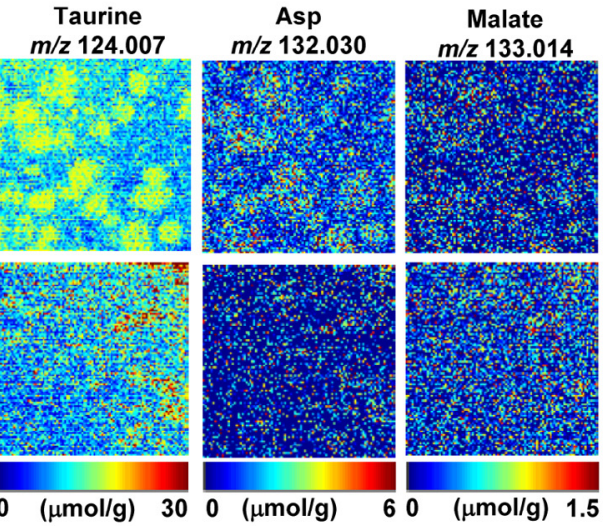

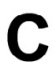

\section{T/Pc ratio} Glutamate

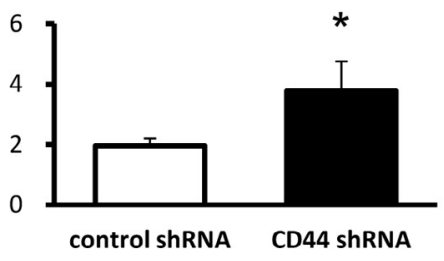

B
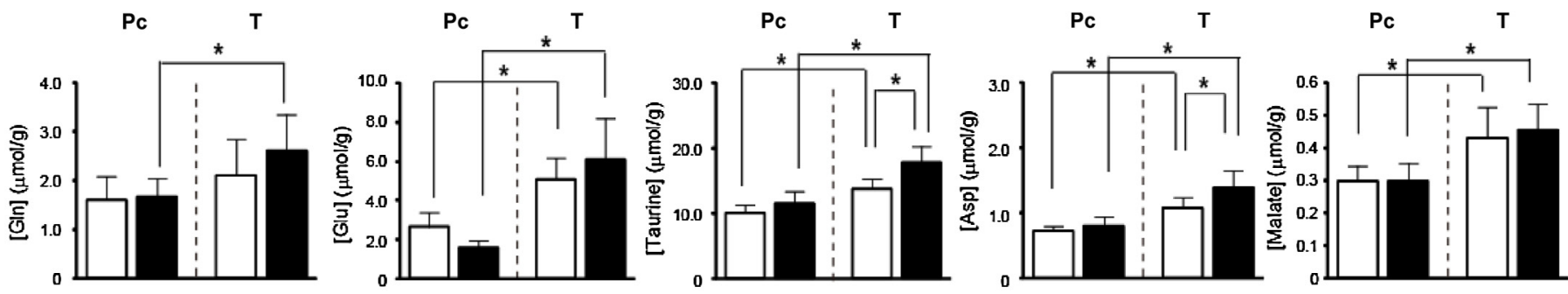

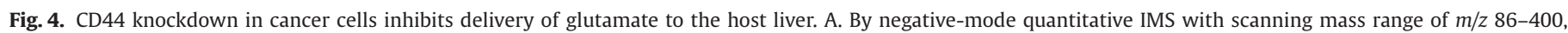

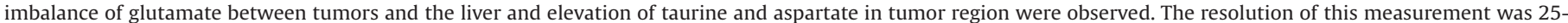

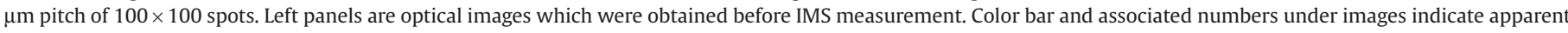

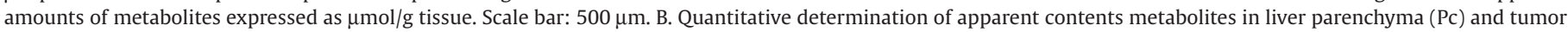

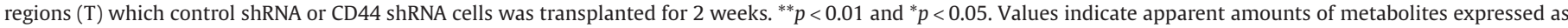

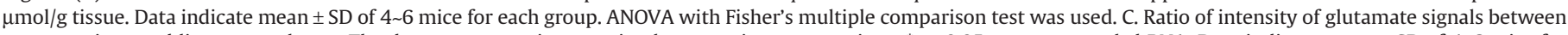

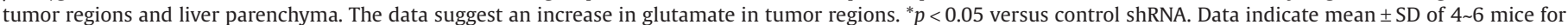
each group. Unpaired Student's $t$-test was used.

changed by shCD44 treatment. On the other hand, contents of spermidine and spermine were significantly greater in tumors than in parenchyma. Of note was that shCD44 treatment significantly suppressed contents of spermidine $(\mathrm{m} / \mathrm{z} 146.166)$ and spermine $(\mathrm{m} / \mathrm{z}$ 203.224 ) in both tumors and parenchyma. Another important change induced by shCD44 was a significant increase in adenosine $(\mathrm{m} / \mathrm{z}$ 268.105) in tumors, which led us to examine energy metabolism using a negative mode MALDI imaging.

\subsection{Negative-mode Q-IMS revealed decreased energy charges and GSH in tumors and the host liver}

Fig. 3 illustrates negative-mode Q-IMS collected by using 9 -aminoacridine as a matrix reagent. As previously described, UDP$\mathrm{N}$-acetyl hexosamine (UDP-HexNAc, $m / z$ 606.074) was accumulated in tumors that did not alter in response to shCD44 treatment. In fasted mice treated with control shRNA, contents of GSH $(\mathrm{m} / \mathrm{z}$ 306.076) were greater in tumors than in parenchyma. Treatment with shCD44 significantly suppressed GSH contents in tumors as well as in parenchyma. Contents of GSSG $(m / z$ 611.144) were greater in tumors than in parenchyma. In response to shCD44, GSSG showed a modest elevation but without statistical significance. Under these circumstances, Total amounts of glutathione (GSH+2GSSG) were significantly higher in tumors than in parenchyma. Of importance was that no suppression of total glutathione was seen in response to shCD44, suggesting that the amounts appear to be compensated by mechanisms independent of CD44/xCT system (Figs. 3A and 3C).
We have recently shown that a portion of glutathione is oxidized under atmospheric MALDI conditions to form glutathione sulfonate $\left(\mathrm{GSO}_{3}{ }^{-}, \mathrm{m} / \mathrm{z} 354.061\right)$ and serves as a substrate for generating glutathione $\mathrm{S}$-sulfonate $\left(\mathrm{GSSO}_{3}{ }^{-}, \mathrm{m} / z\right.$ 386.033) in the presence of endogenous $\mathrm{HS}^{-}$. In other words, $\mathrm{GSSO}_{3}{ }^{-}$serves as an indicator of endogenous $\mathrm{HS}^{-}$generation [10]. These metabolites in tumors were suppressed by shCD44, while the decrease in $\mathrm{GSSO}_{3}{ }^{-}$was marginally significant (Figs. 3A and 3C).

Fig. 3B illustrates alterations in energy metabolism in response to shCD44 treatment. In fasted mice, ATP contents were significantly greater in tumors than in parenchyma. Based on data of ADP and AMP, energy charge (EC) was calculated as ratio images; as seen, EC was higher in tumors than in parenchyma. Furthermore, shCD44 treatment in tumors significantly suppressed EC values not only in tumors but also in parenchyma, suggesting that CD44 in cancer cells mediates mutual interplay for maintaining energy metabolism in vivo.

\subsection{Negative-mode Q-IMS reveals that CD44 causes glutamate imbalance between tumors and the liver}

Tumors turned out to accumulate significantly greater amounts of glutamate than parenchyma (Figs. $4 \mathrm{~A}$ and $4 \mathrm{~B}$ ). In response to shCD44, contents of glutamate $(m / z 146.045)$ in parenchyma appeared to decrease with marginally significant levels, while those in tumors conversely displayed a modest elevation. We then calculated T/Pc ratio of glutamate to examine differences between control shRNA and shCD44 groups, showing a significant 
elevation of the ratio in response to shCD44 treatment (Fig. 4C). Considering that CD44/xCT requires glutamate excretion to uptake cystine into cells, these results suggest that CD44 knockdown in cancer cells helps accumulate glutamate in tumors and decrease the delivery of cystine from parenchyma.

Another important observation was the fact that shCD44 treatment increases contents of taurine $(\mathrm{m} / \mathrm{z} 124.007)$ and aspartate $(\mathrm{m} / \mathrm{z}$ 132.030 ) in tumors but not in parenchyma; the interpretation of these findings will be discussed later.

\subsection{Metabolome analyses of HCT116 cells in culture}

Fig. 5 illustrates differences in metabolomic profiling between HCT116 cells treated with control shRNA and those with shCD44 in culture. In these experiments, the cells were cultured for $72 \mathrm{hrs}$ at which no difference in cell growth was observed (Fig. 1D). CE-MS analyses revealed that shCD44 treatment decreased significantly total amounts of metabolites belonging to methionine salvage pathway (MS; spermidine and spermine) and remethylation (RM) and transsulfuration (TS) pathways; amounts of metabolites residing above cysteine in Fig. $5(\Sigma(\mathrm{MS}+\mathrm{RM}+\mathrm{TS}))$ in shCD44-treated cells were significantly smaller than those treated with control shRNA. Of note is the observation that, despite decreased expression of CBS in response to CD44 knockdown, cystathionine is not decreased. Such observation appeared consistent with a notion that CD44 knockdown may increase supply and delivery of the MS and RM substrates to the downstream pathway.

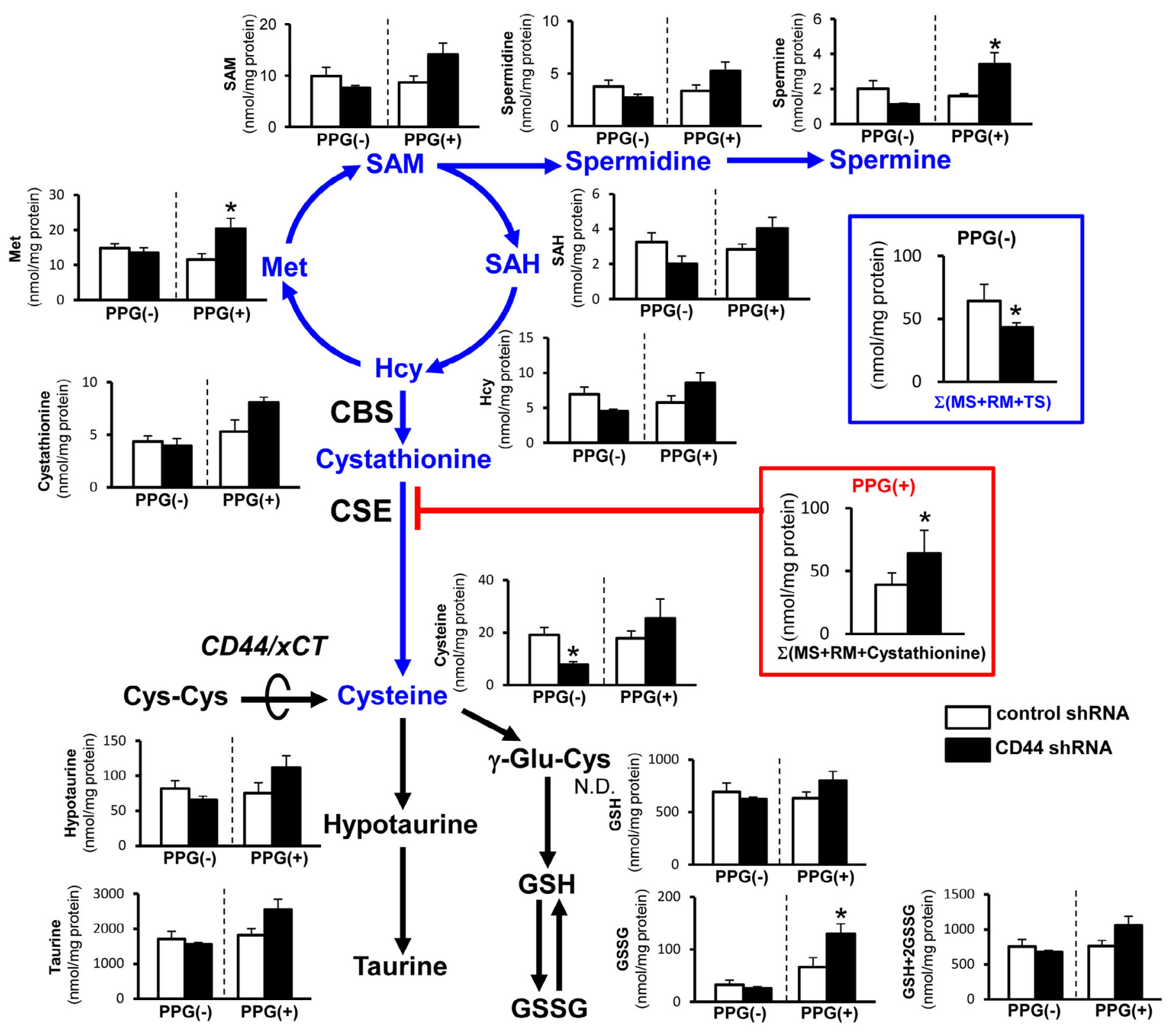

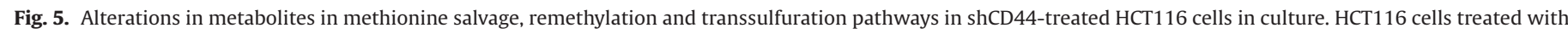

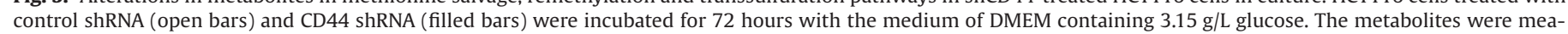

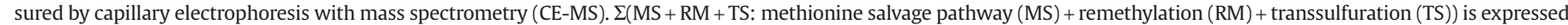

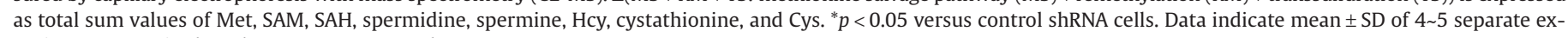
periments. Unpaired Student's $t$-test was used. 

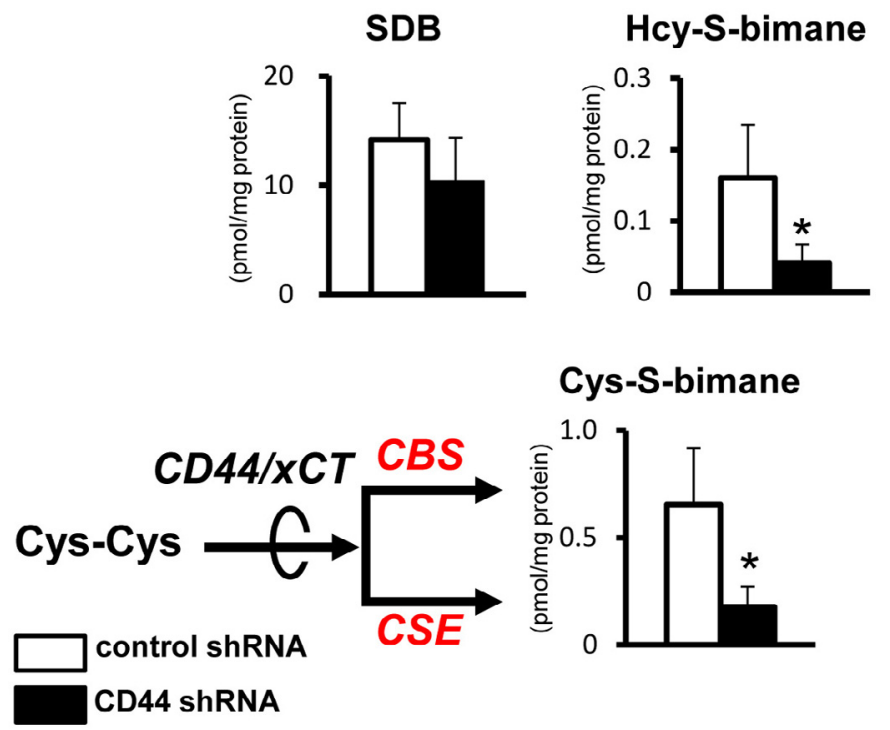

\section{Cys-S-bimane}
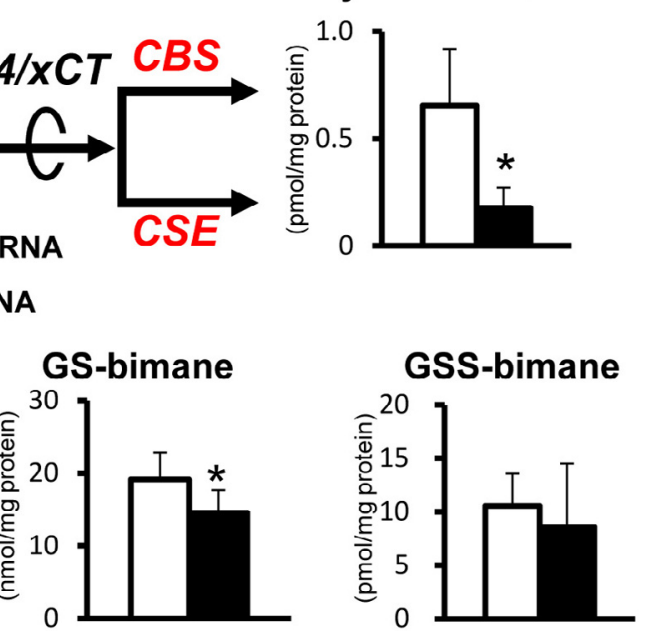

Fig. 6. Effects of shCD44 on reactive cysteine persulfide and related persulfide compounds detected by monobromobimane derivatization methods. ${ }^{*} p<0.05$ versus control shRNA cells. Data indicate mean \pm SD of 6 separate experiments. Unpaired Student's $t$-test was used.

We also examined effects of CSE inhibition by propargylglycine (PPG) in the control and shCD44-treated HCT116 cells in culture (right panels of individual graphs of Fig. 5). Interestingly, PPG treatment significantly increased methionine and spermine and caused marginally significant increases in SAM, SAH, spermidine and homocysteine (Hcy); as a result, the PPG treatment caused a significant elevation of $\Sigma(\mathrm{MS}+\mathrm{RM}+$ cystathionine ) values in shCD44treated cells but not in the control cells. PPG treatment also exhibited a significant elevation of GSSG but not that of GSH. Collectively, combined treatment with CD44 knockdown and PPG appeared to increase metabolites of remethylation cycle and decreased the antioxidative capacity of the cancer cells.

Since CE-MS protocols include treatment with acid that disturbs accurate GSH measurements, we attempted to stop redox conversion of the compound by derivatization using MBB. This technique also benefits measurements of reactive thiol compounds including cysteine persulfide and glutathione persulfide in the cells. As seen in Fig. 6, amounts of cysteine persulfide and homocysteine persulfide that are thought to be generated through CBS and CSE from cystine (Cys-Cys) and homocystine (Hcy-Hcy), respectively, were significantly reduced by shCD44 treatment. On the other hand, glutathione persulfide adduct (GSS-bimane) was not significantly suppressed by shCD44 treatment. However, amounts of GSbimane adduct were significantly suppressed. Considering that cysteine persulfide is a primary product of varied reactive persulfides generated by CBS and CSE using cystine as a substrate [5], these results suggested that CD44 expression is necessary to maintain contents of reactive cysteine persulfides and GSH in cancer cells.

These results collected from experiments in vitro as well as those in vivo led us to hypothesize that cancer cells consume metabolites belonging to MS, RM and TS pathways as an adaptive response against CD44 knockdown. In order to test this hypothesis, effects of either PPG for blocking CSE or cessation of methionine or cystine in culture were examined in the same cell culture system (Fig. 7). The control shRNA-treated cells were able to maintain the cell number in the presence of PPG, while shCD44-treated cells exhibited a significant reduction of the cell number, indicating greater dependence on transsulfuration pathway for survival (Fig. 7A). In the absence of methionine in the culture medium, both cell types exhibited significant decreases in the cell number, showing 80\% drop versus the methionine-containing controls. In the absence of methionine, shCD44-treated cells displayed greater sensitivity than the cells treated with control shRNA (Fig. 7B). These results suggest

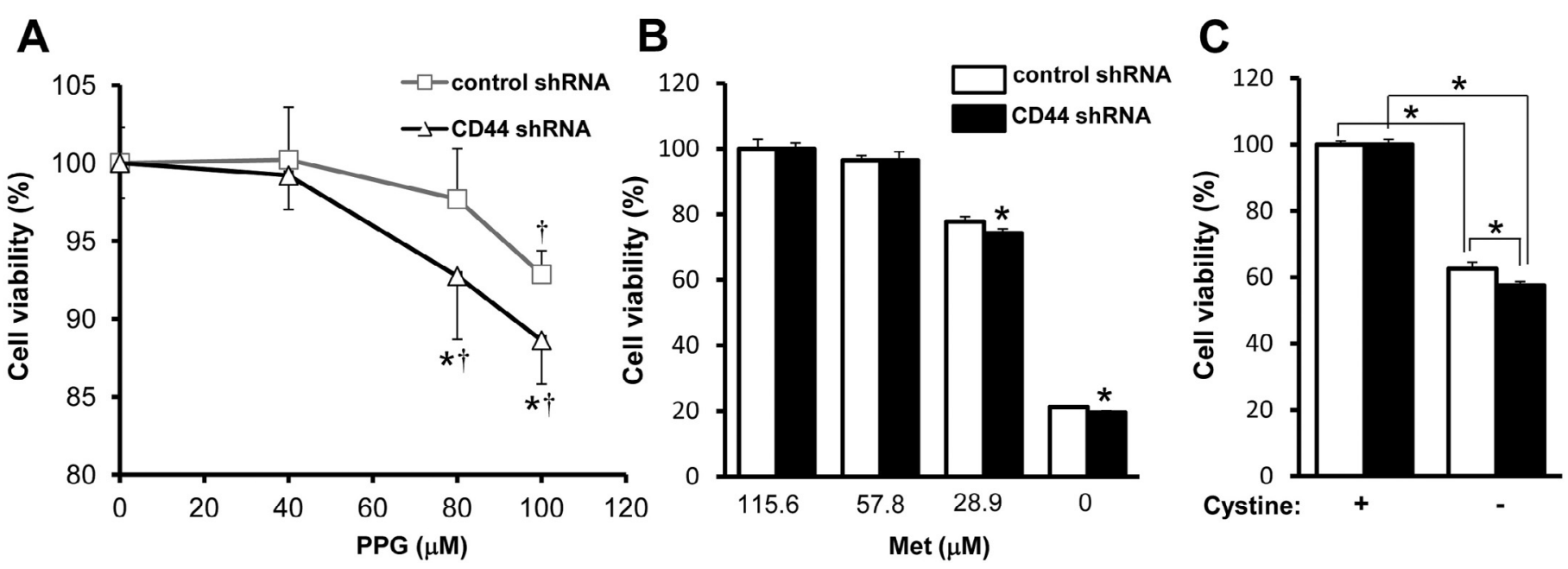

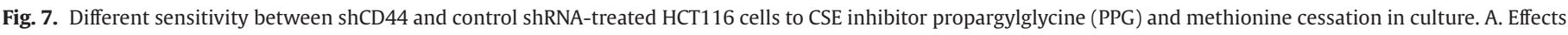

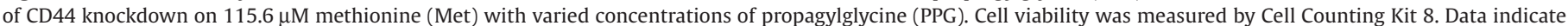

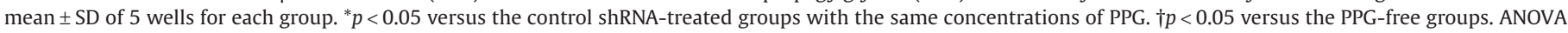

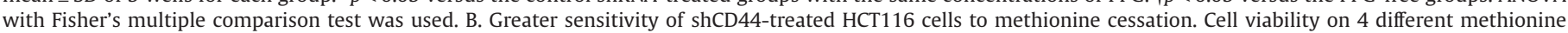

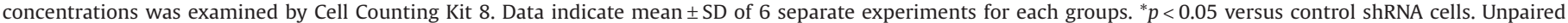

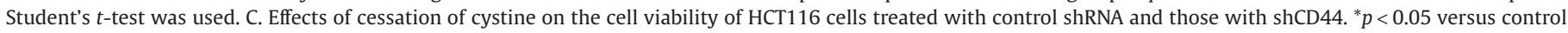
shRNA cells. ANOVA with Fisher's multiple comparison test was used. 
that shCD44-treated cancer cells depend on methionine and its related metabolites to greater extents than the control cells. We also tested effects of cessation of cystine on the cell viability (Fig. 7C). As seen, cessation of cystine significantly decreased the cell viability approximately by $40 \%$, while shCD44-treated cells exhibited greater sensitivity than those treated with the control shRNA.

It was technically difficult to examine the effects of methionine cessation on metabolome because the majority of the cells lost their viability. Since the cystine cessation caused a modest cell injury, we attempted to compare the methionine-related metabolome between the cells in the presence or absence of cystine (Fig. 8). As seen, cessation of cystine caused a significant elevation of $\Sigma(\mathrm{MS}+\mathrm{RM}+\mathrm{TS})$ values in both control shRNA- and shCD44treated HCT116 cells. These results suggest that metabolites belonging to methionine salvage and remethylation pathways are compensated in response to cystine cessation through CD44independent mechanisms.

\section{Discussion}

4.1. CD44 in cancer cells regulates tumor-host metabolic interactions in vivo

We showed that targeting CD44 in cancer cells does not only affect their metabolic systems but also alters metabolic responses of the liver as a host tissue. Up to now, CD44 has been shown to interact with $\mathrm{xCT}$ in many cancer cell lines, and its down-regulation lowers the stability of $\mathrm{xCT}$ that decreases incorporation of cystine and cysteine, compromising the capacity of glutathione to ameliorate oxidative stress $[17,18]$. On the other hand, CD44 interacts with PKM2 to maintain Warburg effect; the CD44 RNA interference causes interaction with PKM2 and accelerates glucose oxidation in mitochondria that secondarily results in oxidative stress and jeopardizes the viability of cancer cells [18]. In this study, shCD44 significantly suppresses tumor growth. Even under these circumstances,

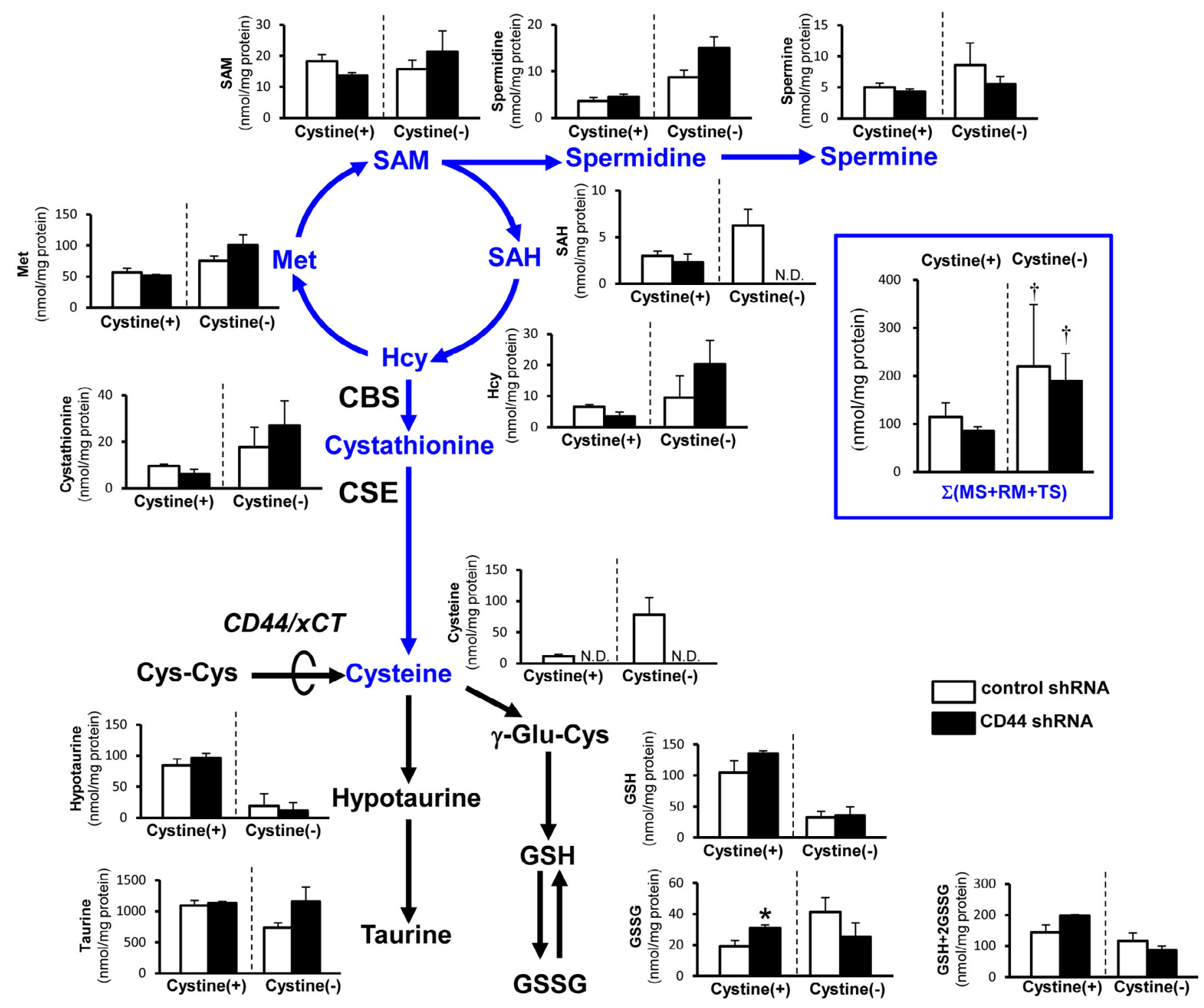

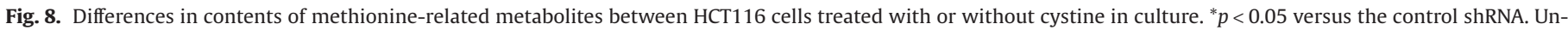

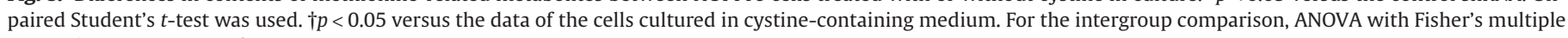
comparison test was used. 
however, little has been known as to whether such alterations in metabolic systems at the side of cancer cells might influence on the host metabolic systems in vivo. Unraveling compensatory metabolic responses of cancer cells might benefit improvement of CD44targeted chemotherapy. Of note is that shCD44 significantly increases the T/Pc ratio of glutamate (Fig. 4), suggesting that downregulation of CD44/xCT inhibits excretion of glutamate from tumors toward the host liver. Since mice are exposed to fasted conditions, such circumstances are likely to decrease availability of glutamate in the liver and may in turn suppress energy metabolism and/or glutathione synthesis that requires ATP. On the other hand, shCD44 treatment is known to accelerate glucose oxidation in mitochondria to generate reactive oxygen species and suppress GSH/GSSG in tumors. Furthermore, such impacts of oxidative stress might influence on extra-tumor regions that could secondarily decrease GSH/ GSSG in the parenchyma. It is not unreasonable to suggest that exchange of cystine and glutamate between cancer cells and the host liver via $\mathrm{xCT} / \mathrm{CD} 44$ system constitute bi-directionally coupled symbiotic systems that depend on each other for maintaining antioxidative capacity in vivo.

\subsection{CD44 knockdown decreases methionine-derived metabolites in cancer cells}

As seen in quantitative data in Fig. 3, CD44 knockdown in cancer cells did not suppress total amounts of glutathione (GSH+2GSSG) in culture and in vivo. These results suggest that GSH suppression in response to CD44 knockdown does not result from substrate shortage but from down-regulation of reducing capacity of the cancer cells. This notion was also supported by marked suppression of GSH/GSSG in tumors in vivo. In other words, even under suppression of extracellular supply of cysteine, the cancer cells were able to maintain total amounts of glutathione. Although the whole mechanisms remain unknown, the results shown in Fig. 5 suggest that CD44 knockdown triggers consumption of methionine and related metabolites (e.g. $\Sigma(\mathrm{MS}+\mathrm{RM}+\mathrm{TS})$ ) [19] to compensate glutathione synthesis in cancer cells. In order to examine which metabolites of methionine-metabolizing pathways play critical roles for cancer survival and development, we conducted experiments investigating sensitivity of cancer cells to methionine cessation and inhibition of transsulfuration pathway in culture. As seen in Fig. 7, the cancer cells treated with shCD44 but not those with control shRNA were sensitive to PPG, a potent inhibitor of CSE, suggesting that downstream metabolites such as cysteine and/or glutathione is necessary to maintain viability of CD44-KD cells. However, suppression of the cell viability by PPG was less than $10 \%$. Of note is that the effects of methionine cessation is far greater than those of PPG for both the control and CD44-KD cells, suggesting greater roles of metabolites belonging to upstream pathways of methionine metabolism. The data shown in Fig. 2 indicating down-regulation of spermine and spermidine in response to CD44-KD support this concept. Considering the previous studies showing critical roles of these metabolites for cancer proliferation and development, marked decreases of the polyamines might play a critical role for inhibiting cancer development in CD44-KD cancer cells in vitro and in vivo. Other metabolites responding to CD44-KD in tumors in vivo involve taurine and aspartate (Fig. 4), while it is unchanged in culture. While mechanisms for these events in vivo require further investigation, the results suggest the presence of metabolic interplay between tumors and the host liver.

Another important finding in the current study is suppression of reactive cysteine persulfides and related persulfide metabolites (Hcy-SH and GSSH). Amounts of GSSH were not altered by CD44 knockdown in culture. This observation is in good agreement with the data collected by Q-IMS showing no alterations in $\mathrm{GSSO}_{3}{ }^{-}$in tumors (Fig. 3). These reactive persulfides are nucleophiles that rapidly react with electrophiles such as many anti-cancer reagents, heme, lipid peroxides and aldehydes. Increased chemosensitivity of CD44-knocked down cancer cells $[4,18,19]$ might result from decreases in these cystine-derived reactive persulfide species.

\section{Conclusion}

Impacts of CD44 knockdown on metabolic systems in cancer and host tissues were examined by Q-IMS combined with metabolomics approaches, suggesting that CD44 expressed in cancer accounts for a key regulator of metabolic interplay between tumor and the host tissue. Among key metabolites indicating alterations in response to CD44 knockdown, spermine, spermidine and reactive cystine persulfides appear to play an important role for cancer development. Further investigation is necessary to provide evidence that these CD44-sensitive metabolites might contribute to cancer proliferation and/or chemoresistance.

\section{Acknowledgments}

The authors thank Professor Takaaki Akaike (Tohoku University) for his advise for interpretation of the data indicating reactive cysteine persulfides. M.S. is the leader of CREST, JST that supports in part metabolome analyses.

\section{References}

[1] Y. Kabuyama, E.S. Litman, P.D. Templeton, S.I. Metzner, E.S. Witze, G.M. Argast, et al., A mediator of Rho-dependent invasion moonlights as a methionine salvage enzyme, Mol. Cell. Proteomics 8 (2009) 2308-2320.

[2] P. Cavuoto, M.F. Fenech, A review of methionine dependency and the role of methionine restriction in cancer growth control and life-span extension, Cancer Treat. Rev. 38 (2012) 726-736.

[3] O. Nagano, S. Okazaki, H. Saya, Redox regulation in stem-like cancer cells by CD44 variant isoforms, Oncogene 32 (2013) 5191-5198.

[4] T. Ishimoto, O. Nagano, T. Yae, M. Tamada, T. Motohara, H. Oshima, et al., CD44 variant regulates redox status in cancer cells by stabilizing the XCT subunit of system xc(-) and thereby promotes tumor growth, Cancer Cell 19 (2011) 387-400.

[5] T. Ida, T. Sawa, H. Ihara, Y. Tsuchiya, Y. Watanabe, Y. Kumagai, et al., Reactive cysteine persulfides and S-polythiolation regulate oxidative stress and redox signaling, Proc. Natl. Acad. Sci. U.S.A. 111 (2014) 7606-7611.

[6] K. Handa, M. Ohmura, C. Nishime, T. Hishiki, Y. Nagahata, K. Kawai, et al., Phosphorescence-assisted microvascular $\mathrm{O}_{2}$ measurements reveal alterations of oxygen demand in human metastatic colon cancer in the liver of superimmunodeficient NOG mice, Adv. Exp. Med. Biol. 662 (2010) 423-429.

[7] A. Kubo, M. Ohmura, M. Wakui, T. Harada, S. Kajihara, K. Ogawa, et al., Semiquantitative analyses of metabolic systems of human colon cancer metastatic xenografts in livers of superimmunodeficient NOG mice, Anal. Bioanal. Chem. 400 (2011) 1895-1904.

[8] Y. Bao, K. Mukai, T. Hishiki, A. Kubo, M. Ohmura, Y. Sugiura, et al., Energy management by enhanced glycolysis in G1-phase in human colon cancer cells in vitro and in vivo, Mol. Cancer Res. 11 (2013) 973-985.

[9] <http://imagej.nih.gov/ij/>.

[10] T. Yamamoto, N. Takano, K. Ishiwata, M. Ohmura, Y. Nagahata, T. Matsuura, et al., Reduced methylation of PFKFB3 in cancer cells shunts glucose towards the pentose phosphate pathway, Nat. Commun. 5 (2014) 3480, doi:10.1038/ ncomms4480.

[11] S. Toue, Y. Sugiura, A. Kubo, M. Ohmura, S. Karakawa, T. Mizukoshi, et al. Microscopic imaging mass spectrometry assisted by on-tissue chemical derivatization for visualizing multiple amino acids in human colon cancer xenografts, Proteomics 14 (2014) 810-819.

[12] K. Hattori, M. Kajimura, T. Hishiki, T. Nakanishi, A. Kubo, Y. Nagahata, et al., Paradoxical ATP elevation in ischemic penumbra revealed by quantitative imaging mass spectrometry, Antioxid. Redox Signal 13 (2010) 1157-1167.

[13] Y. Sugiura, M. Kashiba, K. Maruyama, K. Hoshikawa, R. Sasaki, K. Saito, et al., Cadmium exposure alters metabolomics of sulfur-containing amino acids in rat testes, Antioxid. Redox Signal 7 (2005) 781-787.

[14] S. Norimizu, A. Kudo, M. Kajimura, K. Ishikawa, H. Taniai, T. Yamaguchi, et al., Carbon monoxide stimulates mrp2-dependent excretion of bilirubin-IX $\alpha$ into bile in the perfused rat liver, Antioxid. Redox Signal 5 (2003) 449-456.

[15] T. Shintani, T. Iwabuchi, T. Soga, Y. Kato, T. Yamamoto, N. Takano, et al., Cystathionine $\beta$-synthase as a carbon monoxide-sensitive regulator of bile excretion, Hepatology 49 (2009) 141-150.

[16] T. Morikawa, M. Kajimura, T. Nakamura, T. Hishiki, T. Nakanishi, Y. Yukutake, et al., Hypoxic regulation of the cerebral microcirculation is mediated by a 
carbon monoxide-sensitive hydrogen sulfide pathway, Proc. Natl. Acad. Sci. U.S.A. 109 (2012) 1293-1298.

[17] O. Nagano, H. Saya, Mechanism and biological significance of CD44 cleavage, Cancer Sci 95 (2004) 930-935.

[18] M. Tamada, O. Nagao, S. Tateyama, M. Ohmura, T. Yae, T. Ishimoto, et al., Modulation of glucose metabolism by CD44 contributes to antioxidant status and drug resistance in cancer cells, Cancer Res 72 (2012) 1438-1448.

[19] T. Hishiki, T. Yamamoto, T. Morikawa, A. Kubo, M. Kajimura, M. Suematsu, Carbon monoxide: impact on remethylation/transsulfuration metabolism and its pathophysiologic implications, J. Mol. Med. (Berl.) 90 (2012) 245254. 